account of the various devices which have been successfully employed, such as over-relaxation, block relaxation, group relaxation and the use of multiplying factors; but the great purpose of each book is, of course, to stimulate the student to develop for himself the techniques which are appropriate to the special problems with which he is confronted.

The scope of these books covers linear algebraic equations, linear ordinary differential equations and certain linear partial differential equations, with a special emphasis on the questions of Laplace and Poisson and the biharmonic equation. Another important group of applications of relaxation methods is to eigenvalue problems for algebraic and differential equations. Quite another field of application is to problems where there are free boundaries the form of which is unknown at the beginning of the investigation. Allen's book also gives an account of the use of triangular nets, of the problem of heat conduction and of Southwell's method of intensification in calculat. ing eigenvalues. Shaw's book also deals with the application of relaxation methods to integral equa. tions, the use of Fox's "difference corrections" and gives tables for computing irregular star first and second derivatives near a boundary.

It is very difficult to compare two such similar works; but perhaps it is fair to say that Shaw's book is the more elementary and Allen's is the more philosophical. Certain omissions from Allen's book are quite deliberate, and the author promises another volume in which he will deal with a number of related topics. It would be extremely interesting to have $a$ careful comparison of the method of relaxation with the method of squares as developed by Thom, Morris's escalator method and the hypercircle method of Synge. When a second edition of this book is called for, it would increase its value if some reference were made to the accuracy of the higher eigenvalues obtained by intensification methods and to Tosio Kato's method for estimating the accuracy of eigenvalues in general.

G. Temple

\section{BELIEFS AND SOCIETY}

\section{African Worlds}

Studies in the Cosmological Ideas and Social Values of African Peoples. Edited by Daryll Forde. Pp. xvii +244 . (Published for the International African Institute.) (London : Oxford University Press, 1954.) 30s. net.

$\mathrm{B}$ now a certain amount is known of the social life of non-Western peoples. In the African field we have analyses of political institutions and of kinship, and several general accounts of diverse social systems. This book is an attempt to discuss the beliefs associated with some of them, to analyse the character and the contexts of the value systems of certain African societies. We are given accounts of the cosmological ideas, myths and social values of nine peoples, of varying economic and political organization, from various parts of Africa, and an introduction by the editor.

For several years it has been one of the tenets of social anthropology that there may be a functional interrelationship between the parts of any social system. This hypothesis has been at least tacitly accepted, and research and analysis based upon it have shown its general validity. Research into religious and magical beliefs has demonstrated a close relationship between the system of social relations and that of values, sanctions, codes of conduct and so on, in any one society. An example is that of witchcraft beliefs. What may at first seem a jumble of superstition is integrated closely with, and derives its significance from, the social organization. It is also seen to form a coherent set of beliefs. Once certain premises are accepted-including some denied by Western scientific thought-then the entire structure built upon them is logical and reasonable. Such a system has two aspects, so far as analysis is concerned: its effectiveness in providing values and sanctions for orderly social interaction, and its coherence as a single set of beliefs. But although beliefs in witches may have a similar function in different societies, their form may vary. Similarly with, say, myths of the creation of the world, such as are described in this book. All these peoples have different ideas about the creation and the relationship of men with God and the world. One can regard these ideas as forming closed systems, quite apart from their place in the total scheme of social values. In other words, there is a distinction between the practical and the metaphysical significance of a set of beliefs. The distinction is implicit in every essay in this book.

A system of values, providing a guide to social behaviour, plays an integral part in any society. The types of organization of these various African societies vary, and with them the nature and significance of ties of kinship, territory and so on, from the great kingdoms of Ruanda and Ashanti to the stateless societies of the Lele and the Abaluyia. It can be expected that this variation will be reflected in the social values held by their members. If social anthropology is a comparative discipline, then here is an obvious case for taxonomy as a means towards understanding.

But it is not at all certain that this is so at the level of the myths and cosmologies also described. Since partly, at least, myths explain the place of men in the world, then the form of the society may be reflected to some extent in their content. Those of the Shilluk kingship provide an admirable example, as giving a means for the comprehension by the Shilluk, through the use of symbols, of the nature of the Shilluk polity. But there is much in Shilluk myth that seems to have no function, in this sense, at all. This is even more true of the cosmologies described, notably the elaborate system of the Dogon. Even here there is consistency, or at least a lack of contra. diction. But this interrelationship is of a very different order from that between the form of social relations of a society and the code of behaviour prescribed by certain of its social values.

In short, this book tries to consider two problems, which are not clearly distinguished: the relationship between society and those of its values which guide social action, and that between society and its myths and cosmological ideas. There is clearly a functional relationship in the first case, but the nature of the relation in the latter is open to doubt. The myths may validate the existing status systems of persons and groups, but the cosmologies seem to defy attempts to analyse them as anything but closed systems of thought. We are given nine excellent and fascinating essays; but these do not, as one feels that perhaps they might have done, combine to make a book which advances our sociological understanding of religious belief. The fact that they do not do so raises the underlying problem of the ultimate limits of sociological analysis.
John Middleton 